\title{
Evaluation of DNA damage and mutation screening of exon 26 of SCN1A gene in patients with epilepsy
}

\author{
Nishu Sekar, Shalaka Ramgir, Yogamaya D Prabhu, Kaviyarasi Renu, Abilash V.G* \\ Department of Biomedical Sciences, School of Biosciences and Technology, VIT University, Vellore-632 014, Tamil Nadu, India
}

\section{A R T I C L E I N F O}

\section{Article history:}

Received 4 January 2017

Accepted 7 November 2017

Available online 12 November 2017

\section{Keywords:}

Epilepsy

SCN1A gene

Genetic instability

BMCyt

SSCP

\begin{abstract}
A B S T R A C T
Background: Epilepsy is one of the most prevalent neurological disorders. Around 50 million people worldwide suffer from Epilepsy, 85\% of them are from the developing countries. It is a most significant as well as common brain disorder worldwide. Sodium channel alpha 1 subunit gene (SCN1A) is most commonly mutated the gene in different forms of epilepsy.

Objective: To screen the genomic damage and SCN1A gene mutation in patients with epilepsy.

Methods: To screen the genetic instability of SCN1A gene using Buccal micronucleus cytome (BMCyt) assay and molecular analysis with Single Strand Conformation Polymorphism (SSCP) technique was used to observe the variations in SCN1A gene.

Results: We found significant differences in buccal cells of patients than controls. So, we can interpret that BMCyt assay would be a minimally invasive biomarker to detect DNA damage and mutation screening in the SCN1A gene with SSCP technique showed no variation in epileptic patients.

Conclusion: These data confirmed that there is certainly DNA damage and no mutations in the SCN1A gene; hence the genetic instability has occurred in epileptic patients.

(C) 2017 Published by Elsevier, a division of RELX India, Pvt. Ltd on behalf of Indian Epilepsy Society.
\end{abstract}

\section{Introduction}

Epilepsy is a chronic neurological disorder, which is the disorder of the nervous system. It is a disorder of the brain characterized by an enduring predisposition to generate epileptic seizures. For a disorder to be called epilepsy, within $24 \mathrm{~h}$ two or more unprovoked epileptic seizures have to occur. An epileptic seizure often results from abnormal excessive neuronal activity in the brain. ${ }^{1}$ A person having epilepsy is said to have repeated seizures and these should be recurrent and unprovoked.

Around 50 million people around the worldwide suffer from Epilepsy and $85 \%$ of them are from developing countries. Epilepsy is one of the most prevalent as well as significant neurological disorder worldwide, without age, race, social class, and national or geographical barriers. It has been found that at least $50 \%$ of all these cases begin in childhood or adolescence. Almost $80 \%$ of the people suffering from epilepsy could lead normal lives if properly treated but in developing countries, $60 \%$ to $90 \%$ of these people receive no treatment at all, due to inadequacies in health care resources, delivery, and social stigma. Each year, it is estimated that 2.4 million new cases occur worldwide

\footnotetext{
* Corresponding author.

E-mail address: abilash.vg@vit.ac.in (A. V.G).
}

Pathophysiology of epilepsy is because of the disturbance in neurological processes leading to the expression of seizures. Genetic analysis is no longer confined to gross chromosomal rearrangements. ${ }^{2}$ Molecular instabilities are focusing into the pathophysiology; but yet the genetic information about the complexity of seizure mechanisms needs to be unraveled.

The mutations in genes which are encoding the voltage-gated sodium channel like SCN1A, SCN2A, SCN3A, SCN9A, SCN1B denotes several epileptic conditions. These genetic mutations show benign familial neonatal-infantile epilepsy (BFNIE) to the full generalized epilepsy with febrile seizure plus (GEFS+) and also mild febrile seizures in Dravet syndrome. Mutations in voltage-gated sodium channels are currently the most significant genetic determinants for epilepsy with SCN1A gene which is the major contributor. They transiently increase plasma membrane conductance to sodium ions in response to depolarizations. ${ }^{3}$ Mutations that reduce sodium currents affect electrical excitability of GABA-ergic interneurons. ${ }^{4}$ SCN1A is the only known epilepsy gene with sufficient sporadic cases to enable determination of the parental origin of the mutations.

SCN1A (Sodium channel alpha 1 sub-unit gene -MIM 182389, GenBank AB093548) is the gene that encodes the sodium channel 1 subunit. It has been found that SCN1A gene is the most commonly mutated gene in different forms of epilepsy. More than $70 \%$ of patients with severe myoclonic epilepsy of infancy (SMEI) have 
mutations in the SCN1A gene. More than 170 mutations of SCN1A are associated with SMEI and SMEI borderland (SMEB).

Approximately $95 \%$ of SCN1A mutations are de novo and the remainder shows familial segregation in generalized epilepsy with febrile seizures plus (GEFS+). Besides SMEI, SMEB, and GEFS+, the phenotypic spectrum of SCN1A also includes intractable childhood epilepsy with generalized tonic-clonic seizures. Focal epilepsy, such as temporal lobe epilepsy, presenting occasionally within the GEFS+ spectrum, was associated with an SCN1A mutation as well. A novel SCN1A mutation was also detected in a family with members affected by simple febrile seizures, with some of them later developing temporal lobe epilepsy. It was recently found that in transgenic and whole SCN1A gene, deletions also occur in a variable percentage $(8 \%-27 \%)$ of patients with SMEI without point mutations in SCN1A. ${ }^{5}$

In the past decades, the understanding of epilepsy has been increasing in several aspects. Advances in the field of molecular genetics have revealed new syndromes and identified numerous hereditary patterns. Based on experimental models, the understanding of the mechanisms underlying seizures and epilepsy has also expanded. And all this has led us to the manufacturing of numerous antiepileptic drugs (AEDs) and other means of treating epilepsy. ${ }^{6}$

Based on the results that have been found in previous studies, it is decided in this study to screen the SCN1A gene for mutations in 20 patients (belonging to the Nilgiri District of Tamil Nadu) with epileptic syndromes to evaluate the prevalence of SCN1A abnormalities in this particular group of patients. All the patients were analyzed for the presence of mutations in the SCN1A gene.

For analyses of DNA damages in the individuals, Buccal cell analysis was performed by using Buccal micronucleus cytome (BMCyt) assay. ${ }^{7}$ This study is based on buccal cell and molecular analysis of the family members affected by epilepsy.

\section{Materials and methods}

\subsection{Study population}

A written informed consent was acquired from all the individuals that were taking part in this particular study. This study was approved by the University Human Ethical Committee of the VIT University. A total number of 20 cases of buccal and blood samples were collected from family members having a history of epilepsy belonging to the Nilgiri district, Tamil Nadu. Detailed information about the family history of each affected individual was recorded in a standard proforma. Epidemiological studies for these cases were done and their clinical records were maintained.

The blood samples from all the 20 affected donors were collected separately by venipuncture and were transferred safely into sterile vials containing EDTA. 10 samples were also collected from healthy or normal family members and were used as controls. On the other hand, aspects such as Basic information, Pedigree analysis, Clinical features, Buccal cells studies, and Molecular studies were also studied.

\subsection{Demographical data}

This data includes basic personal details such as name, age, sex and medical history of all the individuals.

\subsection{Clinical analysis}

This implements the information on the physical signs and symptoms of the patients (epidemiology). Based on the clinical features, a questionnaire was prepared and given to every sampling individual to answer and this was done with their consent. The main questions were based on their health histories and difficulties, consciousness, duration, aura, family history and onset of the patients. In all the subjects' pedigree analysis was carried out using Cyrillic programme.

\subsection{Genetic analysis}

\subsubsection{Buccal micronucleus cytome assay}

Studies conducted on analyzing the buccal cells of the individuals by using buccal micronucleus cytome assay. First of all the individuals from whom the buccal cell samples were to be collected, were asked to rinse their mouths thoroughly with water to remove any unwanted debris that might appear on the slides while observing. Then this process continues with rubbing the inside of both cheeks using a cytobrush. The cells were then collected in tubes containing $3 \mathrm{ml}$ sterile saline and stored for future use. On the other hand, we can also directly prepare the slides without delaying the protocol. The slides were prepared by taking the stored buccal cells from the sterile containers or directly after swapping the buccal cells from inside the cheeks. An appropriate amount of the buccal cells were suspended in a small quantity of freshly prepared fixative. Then a test slide was prepared by gently placing a drop of the cell suspension on a clean glass slide and dried immediately on a hot plate $\left(40^{\circ} \mathrm{C}\right)$. Slides for both patient and control samples were prepared.After the slides have dried, they were then stained with $4 \%$ Giemsa solution for $4 \mathrm{~min}$ and destained in double distilled water for $2 \mathrm{~min}$. These slides were scored under the oil immersion objective lens (100X) of the light microscope (Magnus MLX), which was attached to a Samsung SDC 313b camera. Each slide was scored with a maximum of 500 buccal cells. The scoring was done in a zig-zag manner covering all areas of the slides. The slides were scored for normal buccal cells and more importantly for abnormal buccal cells. Abnormal buccal cells were scored based on the categories of binucleates, micronucleus, nuclear buds, fragmented and karyolysed buccal cells. The numbers were noted and the pictures of these abnormal buccal cells were taken. ${ }^{7,8}$

\subsection{Molecular analysis}

DNA was extracted from $2 \mathrm{ml}$ venous blood according to lab protocol $^{9}$ and stored at $-20^{\circ} \mathrm{C}$. Quantification of DNA was done by using a Biophotometer (Eppendorf). After the quantitative analysis of extracted DNA, it was checked in $1 \%$ agarose gel electrophoresis. The extracted DNA samples were amplified using PCR and analyzed for polymorphisms by using SSCP analysis.

Polymerase Chain Reaction (PCR) which was carried out in Master Gradient Thermal Cycler (Eppendorf) with a specific programme for a specific primer which is in the Biotechnology lab, SMV, VIT University using a forward primer as $5^{\prime}$-AGGACTCTGAACCTTACCTTGG-3' and reverse primer as 5'-TGTACATGTTCACCACAACCAG-3'. PCR Reaction Mixture used for amplification of Exon 26 of SCN1A gene is described in Table 1. DNA sample $(4 \mu \mathrm{l})$ was amplified for 35 cycles with initial denaturation for $5 \mathrm{~min}$ at

Table 1

PCR REACTION MIXTURE USED FOR AMPLIFICATION OF EXON 26 OF SCN1A GENE.

\begin{tabular}{ll}
\hline Master mix & Reaction-I \\
\hline 2X PCR Red master mix & $5 \mu \mathrm{l}$ \\
Forward primer $(10 \mathrm{pM} / \mu \mathrm{l})$ & $1.5 \mu \mathrm{l}$ \\
Reverse primer $(10 \mathrm{pM} / \mu \mathrm{l})$ & $1.5 \mu \mathrm{l}$ \\
Milli-Q Water & $8 \mu \mathrm{l}$ \\
Genomic DNA $(20 \mathrm{ng} / \mu \mathrm{l})$ & $4 \mu \mathrm{l}$ \\
Total volume & $20 \mu \mathrm{l}$ \\
\hline
\end{tabular}


$95^{\circ} \mathrm{C}$ followed by denaturation at $95^{\circ} \mathrm{C}$ for $45 \mathrm{~s}$, annealing at $57^{\circ} \mathrm{C}$ for $45 \mathrm{~s}$, extension for $1 \mathrm{~min}$ at $72^{\circ} \mathrm{C}$ and final extension for $10 \mathrm{~min}$ at $72{ }^{\circ} \mathrm{C}$ (Table 2). The PCR products were separated by electrophoresis on $2 \%$ agarose gel containing $5 \mu$ l ethidium bromide $(50 \mu \mathrm{g} / \mu \mathrm{L})$ and were visualized using a UV Transilluminator (Medox). PCR products were used further for SSCP analysis.

\subsection{SSCP analysis}

In this process, the single-stranded nucleic acids are separated based on their differences in sequence (single base pairs). Also, the mobility of the single-stranded DNA is affected by very small changes in sequences which cannot be detected in doublestranded DNA. Here, a single nucleotide change could affect the mobility of the strands. Hence SSCP is another important technique in this study to help us to analyze the changes and polymorphisms which might be the results in mutations of the SCN1A gene. ${ }^{10}$ So finally, SSCP technique was performed by a modified protocol that was already standardized in Biomedical Genetics Research Laboratory, VIT University, Vellore ${ }^{11}$ to find out the polymorphisms in exon 26th of SCN1A gene.

\section{Results}

The results were gathered by carrying out detailed Buccal cells analysis and Molecular analysis of the samples obtained from 20 family members from the Nilgiri District, Tamil Nadu, who are having epilepsy.

\subsection{Demographical data}

Besides the study based on analyzing buccal cells and polymorphisms of the SCN1A gene, other information like age, sex, communication problems, social interaction, sensory response, playing and behavior of the individuals was collected for better analysis.

Out of 20 cases of epilepsy, 9 members were males and 11 members were females. The age difference between the members is not to a great extent. From 20 members, 6 members studied were below the age of 10 years old, 4 members below 20 years old, 4 members between the age of 20-40 years and 6 of them were above 40 years old. Hence, the ages range from adolescence, youths, and adults, but most of the affected individuals were below 15 years.

\subsection{Clinical analysis}

In screening table (Table 3) of participants certain basic information as well as the clinical features of the patients suffering from epilepsy has been mentioned. It also shows the information of age, sex, consciousness, duration of seizure, aura, and the onset of the patients. Fig. 1 show the pedigree of the epileptic patient's family. The darkened figures are family members affected with

Table 2

PCR CONDITIONS.

\begin{tabular}{lll}
\hline Reaction & Temperature & Duration \\
\hline Initial denaturation & $94-96^{\circ} \mathrm{C}$ & $1-9 \mathrm{~min}$ \\
Denaturation & $94-98^{\circ} \mathrm{C}$ & $20-30 \mathrm{~s}$ \\
Annealing & $57^{\circ} \mathrm{C}$ & $20-40 \mathrm{~s}$ \\
Extension & $75-80^{\circ} \mathrm{C}$ & $30 \mathrm{~s}$ \\
Final extension & $70-74^{\circ} \mathrm{C}$ & $5-15 \mathrm{~min}$ \\
On hold & $4-15^{\circ} \mathrm{C}$ & $\infty$ \\
\hline
\end{tabular}

epilepsy. The age of the affected family members is also noted below the darkened figures.

\subsection{Genetic instability study}

The results of buccal cell analysis were based on the normality and abnormality in their morphology and appearance. Their appearance was viewed under the categories of -Mono- nucleate buccal cells (A normal cell with only one nucleus), Bi-nucleate buccal cells (Having two nucleus), Micronuclei buccal cells (A small micronucleus in addition to the existing larger nucleus), Nuclearbud buccal cells (Buds sprouting out from the Nucleus), Fragmented buccal cells (Fragmented nucleus i.e more than normal sized nucleus), Karyolysed buccal cells (The nucleus is degenerating, where there is a decrease in the concentration and contrast of the nucleus). From bi-nucleate to karyolysed buccal cells are the abnormal forms of buccal cells.

In this study, different types of buccal cells belonging to Epileptic patients were observed under the microscope. The pictures are described as Mono-nucleate buccal cells (normal buccal cells) in Fig. 2A, Bi-nucleate buccal cells in Fig. 2B, Fragmented buccal cells in Fig. 2C, Karyolysed buccal cells in Fig. 2D. The slides containing the buccal cells were scored under the oil immersion objective lens (100X) of the light microscope (Magnus MLX), which was attached to a Samsung SDC 313b camera.

The results of buccal cell analysis in control/normal individuals are represented in (Tables 4). This particular table shows how many normal and abnormal buccal cells were seen in each normal individual (control). The results of buccal micronucleus cytome assay analysis of epileptic patients is represented in (Table 5). The statistical results of control and patient buccal cell analysis are represented in (Table 6), which shows how many abnormal buccal cells are seen in each epilepsy patient and in which abnormal form. In Table 6 , the total number, mean and standard deviation of binucleate buccal cells, micronuclei buccal cells, nuclear buds buccal cells, fragmented buccal cells and karyolysed buccal cells in both patients and control individuals were compared. The total numbers of patients were 20, while control/normal individuals were 10 in numbers.

In controls, the total abnormal cells were 41 out of 5000 buccal cells, in which the percentage of abnormal cells were $0.82 \%$ and the frequency of total abnormal cells $( \pm S D)$ were $8.2 \pm 11.4$. However, in patients, the total number of abnormal buccal cells was 516 out of 10,000 buccal cells, in which the percentage of abnormal cells was $5.16 \%$ and the frequency of total abnormal cells $( \pm \mathrm{SD})$ was $103.2 \pm 158.7$.

From the results that were achieved, it clearly shows that the percentage and frequency of abnormal buccal cells of patients were significantly higher than that of the abnormal buccal cells in controls.

In Fig. 3, the graphical representation of abnormal buccal cells seen in both controls and in affected individuals. The X-axis represents the types of abnormal buccal cells and the Y-axis shows the number of abnormal buccal cells. In both cases, binucleated buccal cells have the most numbers which are 379 cells in patients and 28 in controls, and nuclear buds have the least which is 3 cells in patients and 0 in controls. The last column shows the total number of abnormal buccal cells in both control and patients. It also shows the difference in abnormal buccal cells between them. Control individuals have a total of just 41 abnormal buccal cells which includes all the types (binucleates, micronuclei, nuclear buds, fragmented and karyolysed). And including of all abnormal buccal cell types, the epilepsy patients have a total of 516 abnormal cells. The difference between control and patient cells is that of 475 cells. 
Table 3

GENERAL DETAILS AND CLINICAL FEATURES OF EPILEPSY PATIENTS.

\begin{tabular}{|c|c|c|c|c|c|c|}
\hline Patient ID & Age & Sex & Consciousness & Duration of seizure & Aura & Onset \\
\hline EPI001 & 12 & M & Clear & $1-5 \mathrm{~min}$ & Variable & Gradual \\
\hline EPI002 & 11 & $\mathrm{~F}$ & Clouded & $1-2 \min$ & Not variable & Gradual \\
\hline EPI003 & 4 & $\mathrm{~F}$ & Clear & $1 \mathrm{~min}$ & Variable & Sudden \\
\hline EPI004 & 6 & M & Clear & $1-5 \min$ & Variable & Sudden \\
\hline EPI005 & 5 & $\mathrm{~F}$ & Clear & $1-2 \min$ & Not variable & Gradual \\
\hline EPI006 & 7 & M & Clouded & $1-2 \mathrm{~min}$ & Variable & Sudden \\
\hline EPI007 & 11 & M & Clear & $1 \mathrm{~min}$ & Not variable & Gradual \\
\hline EPI008 & 24 & $\mathrm{~F}$ & Clear & $1-5 \mathrm{~min}$ & Variable & Gradual \\
\hline EPI009 & 26 & $\mathrm{~F}$ & Clear & $1-2 \mathrm{~min}$ & Variable & Sudden \\
\hline EPI010 & 55 & $\mathrm{~F}$ & Clouded & $1-7 \mathrm{~min}$ & Variable & Gradual \\
\hline EPI011 & 13 & M & Clear & $1 \mathrm{~min}$ & Not variable & Gradual \\
\hline EPI012 & $2+$ & M & Clear & $1 \mathrm{~min}$ & Not variable & Sudden \\
\hline EPI013 & 56 & M & Clouded & $5-10 \mathrm{~min}$ & Variable & Gradual \\
\hline EPI014 & 66 & $\mathrm{~F}$ & Clouded & $1 \mathrm{~min}$ & Variable & Sudden \\
\hline EPI015 & 45 & $\mathrm{~F}$ & Clear & $1-5 \mathrm{~min}$ & Not variable & Gradual \\
\hline EPI016 & 35 & M & Clear & $1-5 \mathrm{~min}$ & Variable & Sudden \\
\hline EPI017 & 30 & $\mathrm{~F}$ & Clouded & $1-5 \mathrm{~min}$ & Not variable & Gradual \\
\hline EPI018 & 6 & M & Clear & $1 \mathrm{~min}$ & Not variable & Sudden \\
\hline EPI019 & 52 & $\mathrm{~F}$ & Clouded & $1-2 \mathrm{~min}$ & Variable & Gradual \\
\hline EPI020 & 45 & $\mathrm{~F}$ & Clouded & $1-5 \mathrm{~min}$ & Not variable & Gradual \\
\hline
\end{tabular}

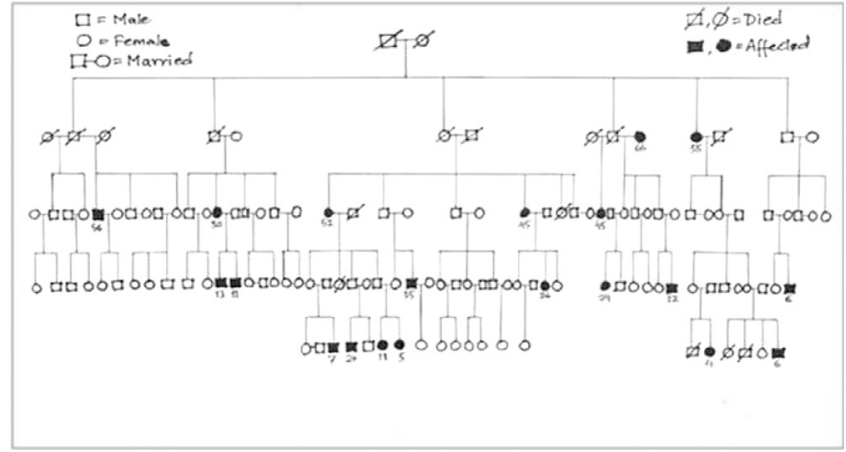

Fig. 1. Pedigree of studied family.

\subsection{PCR analysis}

After DNA extraction and DNA quantification, the DNA samples of the patients were amplified using PCR process. The PCR products were then run under a $2 \%$ agarose gel electrophoresis to check the qualities of the amplified DNA products of the samples that were collected. The amplified DNA samples ran on a $2 \%$ agarose gel electrophoresis with $100 \mathrm{bp}$ DNA ladder. After using forward and reverse primers for PCR, bands were seen at $589 \mathrm{bp}$ for SCN1A.

\subsection{SSCP analysis}

For analyzing genetic variations in SCN1A gene SSCP analysis was performed for Exon 26 of SCN1A gene. SSCP analysis of this gene was carried out in 11 cases of epilepsy samples. For epilepsy patients, SSCP analyses indicating no variations in the bands were observed. For a better result or knowledge of any variations in the $\mathrm{SCN} 1 \mathrm{~A}$ gene, it needs to undergo gene sequencing and further studies on this particular gene.

\section{Discussion}

To evaluate the molecular aspects of epilepsy, this study was designed to analyze the basis of DNA damages using buccal micronucleus cytome (BMCyt) assay and analysis of SCN1A gene mutations using SSCP analysis in the particular family of epileptic patients. And from this study, it may be concluded that the genetic instability has occurred in epileptic patients. Till now around 700 SCN1A mutations have been studied in association with seizures. These studies making the SCN1A gene which is most commonly known mutated gene for the monogenic epilepsy conditions. ${ }^{12}$ Numerous phenotypic expressions are the hallmark of mutations in SCN1A gene ${ }^{13}$ such as from the febrile seizures and GEFS ${ }^{+50}$ to the Dravet syndrome. ${ }^{14}$ Human GEFS $^{+}$mutations (all missense mutations so far) which are present in Dravet syndrome generally lead to loss of function, whereas $\mathrm{GEFS}^{+}$mutations when introduced into the orthologous mouse this gene suggests the general outcome of deleterious SCN1A mutations in decreased activity of GABAergic interneurons. ${ }^{15}$ Most of the epileptic patients are having SCN1A-associated Dravet syndrome which is due to de novo mutations whereas $5 \%$ of them appear in $\mathrm{GEFS}^{+}$families where the associated phenotypes in other family members are less severe. Molecularly, it is still unsolved in Dravet syndrome in about $20 \%$ of the clinically diagnosed cases. ${ }^{16,17}$ Some of the cases are observed with SCN1A copy number variations detected by multiplex ligation-dependent probe amplification. ${ }^{18}$ The SCN1A missense mutations in Dravet syndrome is associated with the gonadal mosaicism (sometimes extending to proven somatic mosaicism) which is an essential molecular mechanism. ${ }^{19-22}$ Mosaicism is not mandatory to look for sporadic cases. The frequency among sporadic cases is not known at present, but the possibility has to be conveyed to families contemplating further children that there is a small but indeterminate risk of recurrence, even if neither parent has the mutation.

Also, in many studies, similar small epilepsy-related lesions at the DNA level has been seen as many single or few base pair deletions or insertions in SCN1A gene. ${ }^{23}$ The spectrum of SCN1Aassociated infantile epileptic encephalopathies has been reported in a syndrome as severe infantile multifocal epilepsy. ${ }^{16}$ SCN1A mutations were identified in three of five patients with this disorder, although the phenotype appears to be milder than malignant migratory partial seizures of early infancy since developmental slowing occurred between ages 16 months and 6 years and the patients were studied between 5 and 20 years of age. There is often difficulty in classifying patients with cryptogenic epilepsies that begin in the first year of life. ${ }^{24,25}$ Patients with severe myoclonic epilepsy in infancy may initially be classified as cryptogenic localization-related epilepsy, which may lead to misguided surgical procedures. 


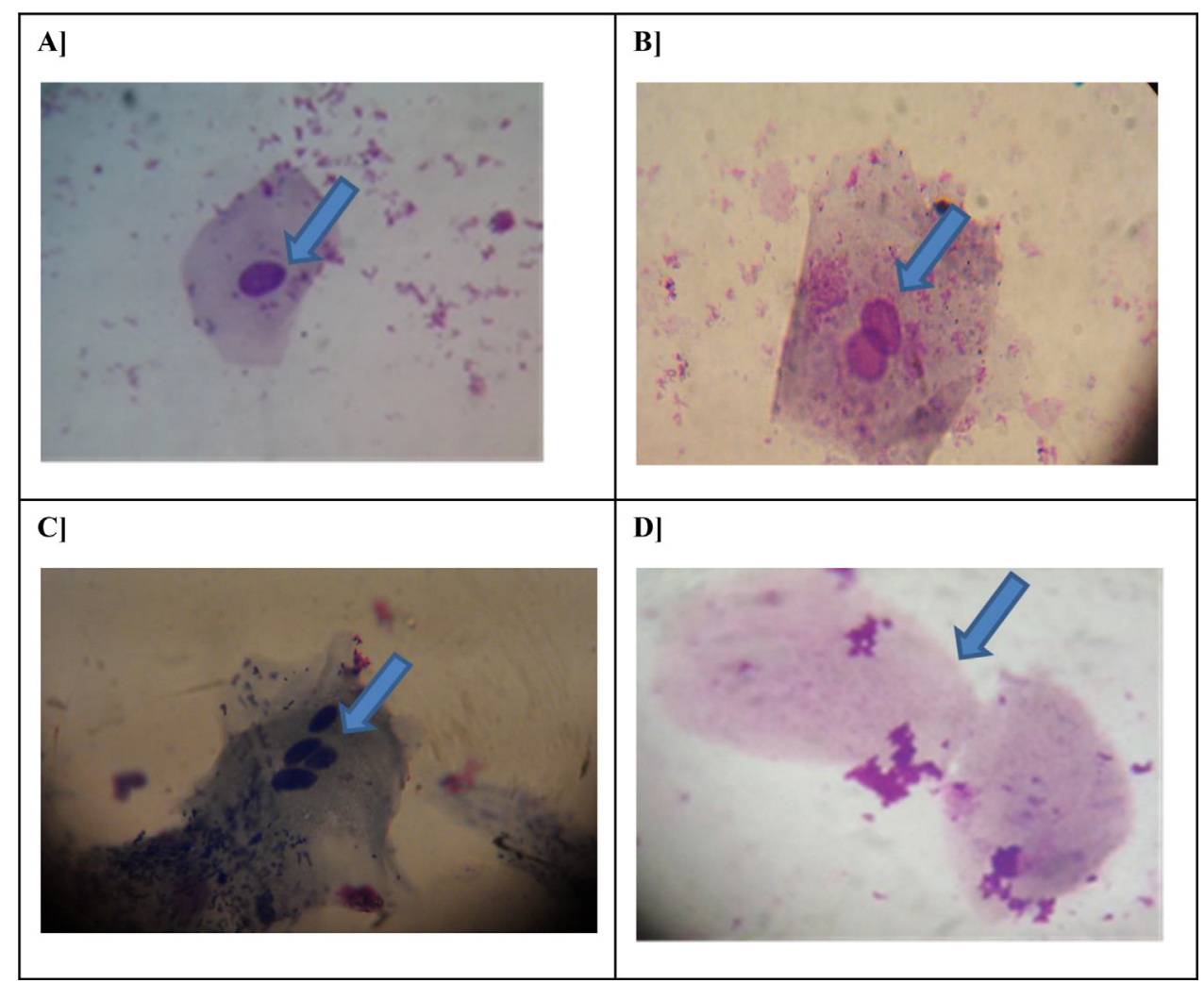

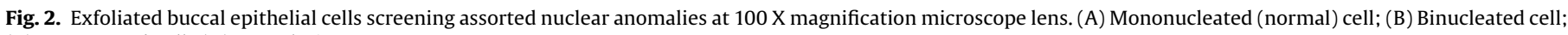
(C) Fragmented cell; (D) Karyolysis.

Table 4

BUCCAL CELLS ANALYSIS OF CONTROL SAMPLES.

\begin{tabular}{|c|c|c|c|c|c|c|}
\hline Control ID & Number of cells scored & Binucleated & Micronuclei & Nuclear buds & Fragmented & Karyolysis \\
\hline Con001 & 500 & 3 & 1 & 0 & 1 & 0 \\
\hline Con002 & 500 & 5 & 0 & 0 & 0 & 0 \\
\hline Con003 & 500 & 4 & 1 & 0 & 0 & 1 \\
\hline Con004 & 500 & 2 & 1 & 0 & 1 & 0 \\
\hline Con005 & 500 & 4 & 2 & 0 & 0 & 1 \\
\hline Con006 & 500 & 2 & 0 & 0 & 0 & 1 \\
\hline Con007 & 500 & 3 & 1 & 0 & 0 & 0 \\
\hline Con008 & 500 & 2 & 0 & 0 & 0 & 0 \\
\hline Con009 & 500 & 2 & 0 & 0 & 0 & 1 \\
\hline Con010 & 500 & 1 & 1 & 0 & 0 & 0 \\
\hline Total & 5000 & 28 & 7 & 0 & 2 & 4 \\
\hline Mean & & 2.8 & 0.7 & 0 & 0.2 & 0.4 \\
\hline Std. dev & & 1.22 & 0.68 & 0 & 0.42 & 0.51 \\
\hline
\end{tabular}

In our study, Buccal Cell Analysis which is the collection of buccal cells and for analyzing them a simple and non-invasive technique has been used. The basic thing is to just swab the inner portion of the cheek and preparing slides from the collected samples. Certain studies have been done for obtaining information on genetic damages by considering the analysis on buccal cells. ${ }^{26}$ So as an initial step of this study, the analysis of buccal cells of the epilepsy patients was done. For detecting genetic damages on the buccal cells, an assay called as Buccal Micronucleus Cytome (BMCyt) assay was improvised. ${ }^{27}$ Taking BMCyt assay as the criteria for analyzing the damages on the buccal cells, five kinds of genetic damages were found on the buccal cells. These were indicated as binucleated buccal cells, micronucleus, nuclear buds, fragmented and karyolysed buccal cells. Although no nuclear buds were seen in any epilepsy samples, few of them were seen in control samples. The results of buccal cell analysis were brought about by pictures of the abnormal buccal cells, their statistics and also with the graphical representations.

After a positive result on detecting genetic damages on the buccal cells of the patients, the second parameter involved in this study which is the molecular analysis of the SCN1A gene was taken up. On this aspect, extraction of DNA samples, amplifying these samples and performing SSCP were the steps taken. The SCN1A gene belongs to a family of genes called SCN (sodium channels). Voltage-gated sodium channels initiate action potentials in brain neurons, and sodium channel blockers are used in therapy of epilepsy. Mutations in sodium channels are responsible for genetic epilepsy syndromes with a wide range of severity, and the NaV1.1 channel encoded by the SCN1A gene is the most frequent target of mutations. ${ }^{28}$ Based on the previous studies that have been done on this particular gene, this study is also concerned with the mutations of SCN1A gene and analyzing it through certain 
Table 5

BUCCAL CELLS ANALYSIS OF EPILEPSY PATIENTS.

\begin{tabular}{|c|c|c|c|c|c|c|}
\hline Patient ID & Number of cells scored & Binucleated & Micronuclei & Nuclear buds & Fragmented & Karyolysis \\
\hline EPI001 & 500 & 13 & 3 & 1 & 1 & 0 \\
\hline EPI002 & 500 & 17 & 4 & 0 & 3 & 0 \\
\hline EPI003 & 500 & 11 & 2 & 1 & 0 & 0 \\
\hline EPI004 & 500 & 36 & 6 & 0 & 0 & 0 \\
\hline EPI005 & 500 & 31 & 8 & 0 & 1 & 0 \\
\hline EPI006 & 500 & 23 & 6 & 0 & 1 & 3 \\
\hline EPI007 & 500 & 13 & 5 & 0 & 0 & 0 \\
\hline EPI008 & 500 & 24 & 15 & 1 & 2 & 1 \\
\hline EPI009 & 500 & 14 & 9 & 0 & 0 & 1 \\
\hline EPI010 & 500 & 115 & 44 & 0 & 0 & 0 \\
\hline EPI011 & 500 & 16 & 3 & 0 & 1 & 0 \\
\hline EPI012 & 500 & 10 & 4 & 0 & 0 & 8 \\
\hline EPI013 & 500 & 45 & 3 & 0 & 2 & 0 \\
\hline EPI014 & 500 & 12 & 1 & 0 & 1 & 1 \\
\hline EPI015 & 500 & 25 & - & 0 & 0 & 0 \\
\hline EPI016 & 500 & 27 & 5 & 0 & 1 & 0 \\
\hline EPI017 & 500 & 10 & 3 & 0 & 3 & 2 \\
\hline EPI018 & 500 & 8 & 4 & 0 & 0 & 0 \\
\hline EPI019 & 500 & 18 & 8 & 0 & 0 & 0 \\
\hline EPI020 & 500 & 11 & 5 & 0 & 0 & 4 \\
\hline TOTAL & 10,000 & 379 & 98 & 3 & 13 & 23 \\
\hline
\end{tabular}

Table 6

STATISTICAL ANALYSIS OF EPILEPSY PATIENTS AND CONTROLS.

\begin{tabular}{|c|c|c|}
\hline Statistical Criteria & Patient & Control; age and sex -related control \\
\hline Total number of Bi-nucleate (BN) cells & 379 & 28 \\
\hline Mean frequency of Bi-nucleate $(\mathrm{BN})$ per cell & $18.95 \pm 9.83$ & $2.8 \pm 1.22$ \\
\hline Total number of Micronuclei (MNi) cells & 98 & 7 \\
\hline Mean frequency of Micronuclei (MNi) per cell & $4.9 \pm 3.3$ & $0.7 \pm 0.68$ \\
\hline Total number of Nuclear-buds (NBUDS) & 3 & 0 \\
\hline Mean frequency of Nucear-buds (NBUDS) per cell & $0.3 \pm 0.48$ & 0 \\
\hline Total number of Fragmented cells & 13 & 2 \\
\hline Mean frequency of Fragmented per cell & $0.65 \pm 0.88$ & $0.2 \pm 0.42$ \\
\hline Total number of Karyolysed cells & 23 & 4 \\
\hline Mean frequency of Karyolysed per cell & $1.15 \pm 2.03$ & $0.4 \pm 0.51$ \\
\hline Total number of BN, MNi, NBUDs, Fragmented and Karyolysed cells & 516 & 41 \\
\hline Mean frequency of BN, MNi, NBUDs, Fragmented and Karyolysed per cell & $103.2 \pm 158.7$ & $8.2 \pm 11.4$ \\
\hline
\end{tabular}

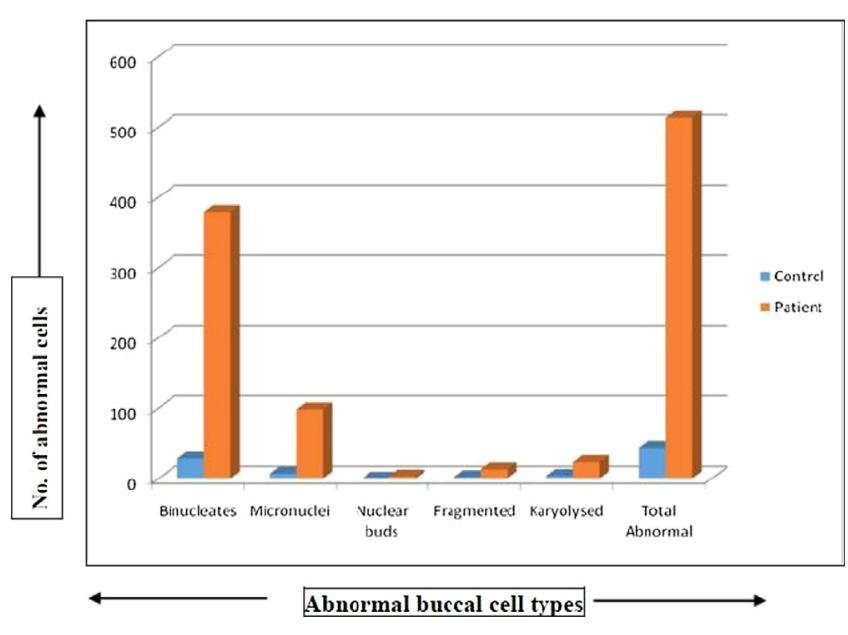

Fig. 3. The abnormal buccal cells observed in normal and control individuals.

parameters as mentioned above. From the various Exons that codes this gene, Exon 26 was considered in this study. For amplifying the particular sequence that codes this gene, specific forward primer and reverse primer were used. In SSCP analysis the bands that were observed in all the affected individuals did not show any variations. As there were no variations observed, further study of the gene and also sending the samples for gene sequencing is required. Only then a clear result can be obtained. The results for molecular analysis of this study were altogether brought about by DNA extraction, DNA amplification, Agarose gel electrophoresis of extracted DNA and amplified DNA and SSCP of the amplified DNA samples.

Further studies need to be done, such as sequencing the mutated genes, so as to know the types of polymorphisms, mutations and variations of the affected gene and hence creating a possibility of a cure for epilepsy. The continuation of such studies on Indian population is important as we know that epilepsy is more prevalent in developing countries. And it is also important to concentrate on a rural population as in our country the data show that there are more epilepsy cases in rural areas than in urban. In order to help those suffering from epilepsy, a study of the disorder, its awareness and finding a cure is of utmost importance. This study was just the first step into knowing about genetic instability in a small population of the rural region suffering from epilepsy and a follow up of the study base will enhance the possibility for a more conclusive evaluation of the study.

\section{Conclusion}

This particular study was done on the family members from the Nilgiri District, Tamil Nadu of which a number of family members belonging to this family had epilepsy. The study is concerned with the genetic instability of SCN1A gene using buccal micronucleus cytome (BMCyt) assay and SSCP analysis in this particular family. 
On the basis of observed results and recent data that were acquired, it had been compared and found that there were definitely higher numbers of DNA damages in the patients than the controls. The results of buccal cell analysis were based on the pictures, sum total, frequency and graphs of the buccal cells of both patients and control samples. On the other hand, molecular analysis results were based on DNA extraction, DNA amplification, and SSCP analysis. After observing bands for amplified DNA samples which were at 400 base pairs, SSCP analysis was followed. In SSCP analysis, there were no variations on the bands of the patient samples. These data established that there is certainly DNA damage and mutations in the SCN1A gene; hence the genetic instability has occurred in epileptic patients. So, it is concluded that there were no confirmed results for SSCP analysis and for better and confirmed results, further study is very much needed and the samples are required to be sent for gene sequencing because there might be variations that might not be detected by SSCP analysis but can be detected by gene sequencing.

\section{Conflict of interest}

The authors declared no conflict of interest.

\section{Acknowledgments}

The authors are grateful to the management of VIT University for providing the excellent facilities to carry out this work.

\section{References}

1. Fisher RS, Boas WV, Blume W, et al. Epileptic seizures and epilepsy: definitions proposed by the international league against epilepsy (ILAE) and the international bureau for epilepsy (IBE). Epilepsia. 2005;46:470-472.

2. Singh R, McKinlay Gardner RJ, Crossland KM, Scheffer IE, Berkovic SF. Chromosomal abnormalities and epilepsy: a review for clinicians and gene hunters. Epilepsia. 2002;43:127-140.

3. Mantegazza M. Catterall WA. Voltage-gated Na+ channels. Epilepsia. 2010;51:9.

4. Catterall WA. Na+ channels and epilepsy. Epilepsia. 2010;51:59.

5. Zucca C, Redaelli F, Epifanio R, et al. Cryptogenic epileptic syndromes related to SCN1A: twelve novel mutations identified. Arch Neurol. 2008;65:489-494.

6. Stafstrom CE. Epilepsy: a review of selected clinical syndromes and advances in basic science. J Cereb Blood Flow Metab. 2006;26:983-1004.

7. Holland N, Bolognesi C, Kirsch-Volders M, et al. The micronucleus assay in human buccal cells as a tool for biomonitoring DNA damage: the human project perspective on current status and knowledge gaps. Mutat Res Rev Mutat Res. 2008;659:93-108.

8. Miller SA, Dykes DD, Polesky HF. A simple salting out procedure for extracting DNA from human nucleated cells. Nucleic Acids Res. 1988:16:1215.

9. Abilash VG, Radha S, Marimuthu KM, et al. Clinical, cytogenetic and molecular analysis of androgen insensitivity syndromes from south Indian cohort and detection and in-silico characterization of androgen receptor gene mutations. Clin Chim Acta. 2016;453:123-130.

10. Melcher Ulrich. Molecular Genetics. .

11. Orita M, Iwahana $H$, Kanazawa $H$, Hayashi $K$, Sekiya $T$. Detection of polymorphisms of human DNA by gel electrophoresis as single-strand conformation polymorphisms. Proc Natl Acad Sci. 1989;86:2766-2770.

12. Claes LR, Deprez L, Suls A, et al. The SCN1A variant database: a novel research and diagnostic tool. Hum Mutat. 2009;30:904-920.

13. Scheffer IE, Berkovic SF. Generalized epilepsy with febrile seizures plus: a genetic disorder with heterogeneous clinical phenotypes. Brain. 1997; 120:479-490.

14. Claes L, Del-Favero J, Ceulemans B, Lagae L, Van Broeckhoven C, De Jonghe P. De novo mutations in the sodium-channel gene SCN1A cause severe myoclonic epilepsy of infancy. Am J Hum Genet. 2001;68:1327-1332.

15. Martin MS, Dutt K, Papale LA, et al. Altered function of the SCN1A voltagegated sodium channel leads to $\gamma$-aminobutyric acid-ergic (GABAergic) interneuron abnormalities. J Biol Chem. 2010;285:9823-9834.

16. Harkin LA, McMahon JM, Iona X, et al. The spectrum of SCN1A-related infantile epileptic encephalopathies. Brain. 2007;130:843-852.

17. Marini C, Mei D, Temudo T, et al. Idiopathic epilepsies with seizures precipitated by fever and SCN1A abnormalities. Epilepsia. 2007;48:1678-1685.

18. Mulley JC, Nelson P, Guerrero S, et al. A new molecular mechanism for severe myoclonic epilepsy of infancy: exonic deletions in SCN1A. Neurol. 2006;67:1094-1095.

19. Depienne C, Arzimanoglou A, Trouillard O, et al. An I. Parental mosaicism can cause recurrent transmission of SCN1A mutations associated with severe myoclonic epilepsy of infancy. Hum Mutat. 2006;27:389.

20. Gennaro E, Santorelli FM, Bertini E, et al. Somatic and germline mosaicisms in severe myoclonic epilepsy of infancy. Biochem Biophys Res Commun. 2006;341:489-493.

21. Marini C, Mei D, Helen Cross J, Guerrini R. Mosaic SCN1A mutation in familial severe myoclonic epilepsy of infancy. Epilepsia. 2006;47:1737-1740.

22. Morimoto M, Mazaki E, Nishimura A, et al. SCN1A mutation mosaicism in a family with severe myoclonic epilepsy in infancy. Epilepsia. 2006;47:17321736.

23. Lossin C. A catalog of SCN1A variants. Brain Dev. 2009;28(31):114-130.

24. Morimoto M, Mazaki E, Nishimura A, et al. Clinical study of catastrophic infantile epilepsy with focal seizures. Pediatr Neurol. 2002;27:369-377.

25. Sarisjulis N, Gamboni B, Plouin P, Kaminska A, Dulac O. Diagnosing idiopathic/ cryptogenic epilepsy syndromes in infancy. Arch Dis Child. 2000;82:226-230.

26. Dlugos DJ, Scattergood TM, Ferraro TN, Berrettinni WH, Buono RJ. Recruitment rates and fear of phlebotomy in pediatric patients in a genetic study of epilepsy. Epilepsy Behav. 2005;6:444-446.

27. Thomas P, Holland N, Bolognesi C, et al. Buccal micronucleus cytochrome assay. Nat Protoc. 2009;4:825-837.

28. Catterall WA, Kalume F, Oakley JC. NaV1.1 channels and epilepsy. J Physiol. 2010;588:1849-1859. 